\title{
Endogenous and Natural Complement Inhibitor Attenuates Myocardial Injury and Arterial Thrombogenesis
}

\author{
Vasile I. Pavlov, MD ${ }^{1}$, Mikkel-Ole Skjoedt, $\mathrm{PhD}^{2}$, Ying Siow Tan, BS ${ }^{1}$, Anne Rosbjerg, B \\ $\mathrm{Sci}^{2}$, Peter Garred, MD, DMSc${ }^{2}$, and Gregory L. Stahl, PhD ${ }^{1}$ \\ ${ }^{1}$ Center for Experimental Therapeutics and Reperfusion Injury, Department of Anesthesiology, \\ Perioperative and Pain Medicine, Brigham and Women's Hospital, Harvard Medical School, \\ Boston MA \\ ${ }^{2}$ Laboratory of Molecular Medicine, Department of Clinical Immunology-7631, Rigshospitalet, \\ University of Copenhagen, Copenhagen, Denmark
}

\begin{abstract}
Background-Coagulation disorders and reperfusion of ischemic myocardium are major causes of morbidity and mortality. Lectin pathway initiation complexes are composed of multimolecular carbohydrate recognition subcomponents and three lectin pathway specific serine proteases. We have recently shown that the lectin pathway specific carbohydrate recognition subcomponent mannose-binding lectin (MBL) plays an essential role in the pathophysiology of thrombosis and ischemia/reperfusion injury. Thus, we hypothesized that the endogenous MBL associated protein, MAP-1, that inhibits complement activation in vitro also could be an in vivo regulator by attenuating myocardial schema/reperfusion injury and thrombogenesis when used at pharmacologic doses in wild type mice.
\end{abstract}

Methods and Results-MAP-1, in two mouse models, preserves cardiac function, decreases infarct size, decreases $\mathrm{C} 3$ deposition, inhibits MBL deposition and prevents thrombogenesis. Further, we also demonstrate that MAP-1 displaces MASP-1, MASP-2 and MASP-3 from the MBL complex.

Conclusions-Our results suggest that the natural, endogenous inhibitor, MAP-1effectively inhibits lectin pathway activation in vivo. MAP-1 at pharmacologic doses represents a novel therapeutic approach for human diseases involving the lectin pathway and its associated MASPs.

\section{Keywords}

myocardial infarction; coagulation; infarction; immunology

\section{INTRODUCTION}

The innate immune response is a 'perfect' system, which through evolution makes the seminal decision to respond against foreign pathogens ${ }^{1}$. Host defense to foreign invaders is mediated by a repertoire of innate immune molecules and receptors able to recognize pathogen-associated molecular patterns (PAMPs), including bacterial surface mannans and glycans, LPS and bacterial DNA CpG motifs ${ }^{1 ; 2}$. Components of innate immunity can

Correspondence: Gregory L Stahl, $\mathrm{PhD}$, Center for Experimental Therapeutics and Reperfusion Injury, Harvard Institutes of Medicine, HIM 845A, 77 Avenue Louis Pasteur, Boston, MA 02115, Phone: (617) 525-5021, Fax: (617) 525-5026, gstahl@zeus.bwh.harvard.edu.

DISCLOSURES: MOS and PG are listed as inventors on a patent application about the use of MAP-1 as an anti-inflammatory agent. The other authors declare no conflicts of interest. 
recognize self-tissue following various insults observed in human disease (i.e., during autoimmunity, transplant rejection, and allergy), as well ${ }^{2-4}$. Recent evidence from our laboratories shows that in addition to mannose and N-acetylglucosamine PAMPs, mannosebinding lectin (MBL) an initiation molecule in the lectin complement pathway (Fig. 1) recognizes endogenous ligands, resulting in induction of inflammatory mediators, tissue injury, vascular remodelling and thrombogenesis in several models of human disease in vivo ${ }^{4-10}$.

Initiation molecules involved in lectin complement pathway activation in humans include MBL and ficolins (i.e., ficolins-1,- 2, and -3), whereas in mice MBL-A and -C are the preeminent initiation molecules ${ }^{11}$. Each of these initiation molecules are associated with serine proteases termed mannose-binding lectin/ficolin associated serine proteases (i.e., MASPs 1, 2, and 3), which are involved in the direct activation of C4 and C2 in the lectin complement pathway and conversion of pro-Factor D to Factor D and cleavage of factor B in the alternative complement pathway ${ }^{12-15}$. The direct activation of the alternative pathway has so far only been clearly documented in rodents. Moreover, they have also been shown to be involved in cleavage of prothrombin to thrombin, cleavage of fibrinogen, activation of FXIII, and cleavage of kininogen (Fig. 1) ${ }^{16-21}$. Inhibition of MBL or MASP-2 protects against ischemia/reperfusion injury, whereas the natural endogenous inhibitor $\mathrm{C} 1$ inhibitor, which also inhibits MASPs in addition to other enzymes (i.e., C1r/s, factor XIIa and kallikrein) also preserves myocardial function following ischemia/ reperfusion 7;9;10;22;23. Thus, initiation molecules of the lectin complement pathway and their associated MASPs are involved in the activation of multiple biologic pathways involved in human disease. Specific inhibition of the lectin pathway has the functional capacity to regulate and attenuate many different biologic pathways and cascade systems in vivo.

Additional truncated protein variants of the MASPs are also associated with MBL and ficolin complexes, including small MBL-associated protein (sMAP or MAp19) ${ }^{24}$, and MBL/ficolin-associated protein-1 (MAP-1) ${ }^{25}$ also named MAp44 ${ }^{26}$. MAP-1 and sMAP are alternative splice variants originating from the $M A S P 1$ and $M A S P 2$ genes, respectively, and lack the serine protease domains. MAP-1 displaces MASP-2 and inhibits MBL- and Ficolin-3-dependent complement activation in vitro ${ }^{25}$, while no conclusive function has been attributed to sMAP. Thus, we hypothesized that MAP-1 is an inhibitor of the lectin pathway in vivo and could be used as a pharmacological inhibitor of MASP mediated diseases. In the present study, we investigated the use of MAP-1 as an inhibitor of lectin pathway activation in two different in vivo models that activate MASP-1 and/or MASP-2 and are MBL-dependent.

\section{METHODS}

All procedures were reviewed and conducted according to the Institute's Animal Care and Use Committee. All experiments were performed under the standards and principles set forth in the Guide for Care and Use of Laboratory Animals, published by National Institute of Health (NIH Publication No. 85-23, Revised 1996).

\section{Animals}

C57BL/6 (WT) mice (8-12 weeks old, Taconic Farms) were used as background controls for genetically modified MBL null mice, as described previously $7 ; 8$. The following groups were investigated in the in vivo studies: 1) WT, 2) MBL null, 3) WT + bovine serum albumin (BSA; control protein at $500 \mu \mathrm{g} / \mathrm{mouse}$; ip), 4) WT + MAP-1 (300 or $500 \mu \mathrm{g} /$ mouse; ip), 5) MBL null + rhMBL (30 $\mu \mathrm{g} /$ mouse; ip), 6) MBL null + rhMBL (30 $\mu \mathrm{g} / \mathrm{mouse}$; 
ip) + MAP-1 (160 $\mu \mathrm{g} / \mathrm{mouse}$; ip). Mice were housed 4 per cage and had unlimited access to water and standard mouse chow.

\section{Competition ELISA assay}

Mannan (Sigma-Aldrich M7504) was immobilized on Maxisorp ELISA plates (Nunc, Denmark) at $10 \mu \mathrm{g} / \mathrm{ml}$ overnight at $4{ }^{\circ} \mathrm{C}$ and served as a ligand for MBL. The plates were washed and blocked in TBS with $0.05 \%$ Tween- 20 and $2 \mathrm{mM} \mathrm{CaCl}_{2}$ before incubation with $0.5 \mu \mathrm{g} / \mathrm{ml} \mathrm{rMBL}$ for 2 hours at $20^{\circ} \mathrm{C}$. In three different experimental settings, serial dilutions of rMAP-1 and rMASP-1, rMASP-2 or rMASP-3, respectively, were mixed in nonadsorbent 96 well plates preceding 2 hours co-incubation at $20^{\circ} \mathrm{C}$ on the $\mathrm{rMBL} / \mathrm{mannan}$ ELISA plates.

Hereafter, immuno-detection was used to assess the binding of rMASP-1, rMASP-2 or rMASP-3 to rMBL. Binding of rMASP-1 and rMASP-3 was detected with $0.5 \mu \mathrm{g} / \mathrm{ml}$ of a monoclonal antibody (mAb) F3-46 reacting with a shared epitope of MASP-1 and -3, but does not cross-react with MAP-1. Similar results were also obtained with a series of other specific MASP-1/-3 mAbs. The mAb producing hybridomas were generated as described previously ${ }^{27}$. Incubation of the primary mAbs was done overnight at $4^{\circ} \mathrm{C}$. A signal was obtained with 45 minutes incubation of HRP-conjugated rabbit anti-mouse IgG at 1:1500 (P0260, Dako, Denmark) and 15 minutes development using ortho-phenylene-diamine (Dako, Glostrup/Denmark). The enzyme reaction was stopped with $1 \mathrm{M} \mathrm{H}_{2} \mathrm{SO}_{4}$. Optical density levels were measured using a V-max Kinetic-reader (Molecular Devices, U.S.A.)

Detection of rMASP-2 binding to rMBL was performed with an anti-MASP-2 rat mAb 8B5 (Hycult Biotechnology, Netherlands) as described above, with the exception that HRPconjugated rabbit anti-rat (P0450, Dako, Denmark) was used as a secondary antibody.

\section{Recombinant proteins}

For these assays we used in-house generated human recombinant proteins that were all expressed in CHO-DG44 cells (rMBL, rMASP-1, rMASP-2, rMASP-3 and rMAP-1) as previously described ${ }^{25 ; 27}$. MAP-1 used in the animal experiments was also produced by the same technique, while recombinant human MBL used in the animal experiments was a gift from Enzon, Inc. USA.

\section{Murine MI/R model}

The murine MI/R model was performed using modifications as described ${ }^{7 ; 9 ; 28}$. Briefly, mice were anesthetized with sodium pentobarbital $(60 \mathrm{mg} / \mathrm{kg})$ for intubation, then ventilated with positive pressure on a SAR Small Animal Ventilator (Model 683, Harvard Apparatus, Holliston, MA, USA) and maintained under anesthesia with isoflurane (1.7 MAC). The chest was opened through a sternotomy and the chest wall retracted using a 5-0 blackbraided silk suture. An 8-0 black-braided silk suture (USSDG, Norwalk, CT) was passed beneath the left anterior descending (LAD) coronary artery approximately $2 \mathrm{~mm}$ from the tip of the left atrium. A 1-2 mm piece of 0-0 suture (Deknatal, Fall River, MA) was placed on the LAD, and the ligation tightened to occlude the artery. After 45 minutes of ischemia, the ligation was loosened and the 0-0 suture removed. Drainage (20GA I.V. Catheter, BD Insyte) was placed through the skin beneath the sternum. The chest was closed using a 5-0 black-braided silk suture (Ethicon). The skin was sutured using a 5-0 black-braided silk suture (Ethicon). The drainage catheter was removed from the thoracic cavity after air was removed. The animal was removed from the respirator and allowed to reperfuse for 4 hours. EKG changes (i.e., ST segment) were monitored and used to establish ischemia and reperfusion. 


\section{Infarct size measurements}

Following reperfusion, mice were anesthetized with sodium pentobarbital. The chest cavity was opened and the LAD coronary artery ligation retightened. The heart was flushed retrograde through the thoracic aorta with $500 \mu \mathrm{l}$ of PBS and then perfused with $200 \mu \mathrm{l}$ of $5 \%$ Brilliant Blue G (Acros). Hearts were excised and cross-sectioned from base to apex into 1-mm slices using a coronal acrylic matrix (Roboz). Sections were incubated in 1\% triphenyltetrazolium chloride (Acros) at $37^{\circ} \mathrm{C}$ for 15 minutes as described $7 ; 10 ; 29$. Following triphenyltetrazolium chloride staining, sections were fixed in 10\% formalin (Sigma-Aldrich) at $4^{\circ} \mathrm{C}$ overnight. Each section of the heart was imaged using a Nikon SMZ800 stereoscopic zoom microscope, digital SPOT Insight camera (Diagnostic Instruments, Inc. USA), and areas calculated using Image $\mathbf{J}$ software (National Institutes of Health, Bethesda, MD). Infarct size was determined by calculating total areas of left ventricular free wall, infarcted tissue, non-ischemic tissue, and ischemic area at risk (AAR). AAR was not significantly different between groups (data not shown).

\section{Echocardiography}

Additional mice underwent experimental MI/R as described above. Transthoracic echocardiographic measurements were used to evaluate cardiac function as described $7 ; 9 ; 28 ; 30$. Echocardiography was performed 4 hours after reperfusion using a Philips Sonos 5500 (Andover, MA, USA) with a 7-15 MHz probe. Ejection fraction (EF) was calculated via long axis length and short axis area measurements of the left ventricle (LV) during systole and diastole as described $7 ; 9 ; 28 ; 30$.

\section{Collection of Blood and Tissue}

Following reperfusion and echocardiography, the chest cavity was opened, the inferior cava vein cut and blood collected from the thoracic cavity. Hearts were excised and embedded in OCT and frozen in liquid nitrogen cooled 2-methylbutane.

\section{Ferric chloride $\left(\mathrm{FeCl}_{3}\right)$ coagulation model}

The mouse model of localized thrombus formation was used as described $6 ; 21 ; 31 ; 32$. Mice were induced and maintained with isoflurane anesthesia and placed in a supine position. An incision was made and the right common carotid artery exposed by blunt dissection. Carotid blood flow was measured with a Doppler flow probe (Transonic) as described ${ }^{6 ; 21}$. Whatman filter paper saturated with $3.5 \% \mathrm{FeCl}_{3}$ was applied to either side of the carotid artery, proximal to the Doppler flow probe. The filter paper was removed 3 minutes after $3.5 \% \mathrm{FeCl}_{3}$ application and the carotid blood flow measured continuously for 30 minutes. Carotid arteries were removed, embedded in OCT and frozen in liquid nitrogen cooled 2methylbutane.

\section{Histology and Immunohistochemistry}

Frozen sections of carotid arteries $(5 \mu \mathrm{m})$ were fixed with $4 \%$ paraformaldehyde for 10 minutes, rinsed with PBS, and followed by incubation for one hour with monoclonal rat anti-mouse MBL-A and MBL-C (Hycult Biotech, The Netherlands; 1:100 in PBS/0.05\% Triton X-100 supplemented with $1 \mathrm{mM} \mathrm{CaCl}_{2}$ ). To control for non-specific staining, isotype control antibody (i.e., rat IgG, Vector Laboratories, Burlingame, CA) was used in place of the rat anti-mouse MBL-A and MBL-C mAbs. After a brief rinse, slides were incubated with biotinylated polyclonal rabbit anti-rat IgG (Dako, Carpinteria, CA; 1:600 in PBS for 45 minutes). Tissue sections were incubated with a Vectastain ABC-AP kit (Vector Laboratories) and MBL was detected with a Vector Red alkaline phosphatase substrate kit (Vector Laboratories). All images were captured using a Nikon Eclipse E400 microscope and analyzed using SPOT imaging software (Diagnostic Instruments). 
Myocardial sections $(7 \mu \mathrm{m})$ were fixed with acetone for 10 minutes, rinsed with PBS and followed by one hour incubation with polyclonal goat anti-mouse C3 (MP Biomedicals, Solon, OH; 1:500 in PBS/0.05\% Triton X-100). After a brief rinse, C3 deposition was detected using donkey anti-goat IRDye800 (Rockland Immunochemicals, Gilbertsville, PA; 1:2000 in PBS for one hour). C3 deposition was visualized using an Odyssey infrared imaging system (LI-COR, Lincoln, NE) and analyzed using Image J software (National Institutes of Health, Bethesda, MD).

\section{MBL and C3 deposition fluorochrome immunosorbent assay (FLISA)}

MBL and MBL-dependent C3 deposition on mannan-coated 384 microtiter plates was performed as previously described ${ }^{33}$. Human sera (2\%) were incubated with vehicle (VBS), anti-MBL mAb (3F8, $10 \mu \mathrm{g} / \mathrm{ml})$ or MAP- $1(5$ or $10 \mu \mathrm{g} / \mathrm{ml})$ for $1 \mathrm{hr}$ at $37^{\circ} \mathrm{C}$ and was then placed in mannan-coated wells and processed for MBL and C3 deposition as described ${ }^{33}$. An additional FLISA assay was also performed by replacing the mannan with Nacetylglucosamine-BSA (GlcNAc-BSA) as the MBL ligand coated to the wells as described ${ }^{10}$. Experimental groups for the GlcNAc-BSA FLISA were vehicle (VBS), Dmannose $(30 \mathrm{mM})$ or MAP-1 $(1,5$ and $10 \mu \mathrm{g} / \mathrm{ml})$. Results from the GlcNAc-BSA FLISA assay were processed the same way as the mannan FLISA assay. Background integrated intensity (II) from the Odyssey readings in both assays consisted of wells coated with VBS only and subtracted from all groups. All groups were performed in triplicate and mannan FLISA was repeated three times $(\mathrm{N}=3)$ and the GlcNAc-BSA FLISA was repeated 5 times $(\mathrm{N}=5)$.

\section{Statistical Analysis}

All statistical analysis was performed using SigmaStatsoftware (SPSS, Chicago, IL, USA). Data are presented as means \pm SEM. Normality and equal variances were checked in each statistical analysis and the one way ANOVA followed by the Student-Newman-Keuls test was used to establish significance between groups in all Figures with the following exceptions. One way repeated measures ANOVA followed by the Holm-Sidak test was used to compare groups in the $\mathrm{FeCl}_{3}$ study. The t-test was used to compare the two WT groups in the analysis of infarct area. $\mathrm{C} 3$ deposition on $\mathrm{N}$-acetylglucosamine-BSA plates was analyzed by a Kruskal-Wallis one way ANOVA on Ranks, followed by the Dunn's method to find differences between groups. $\mathrm{P}<0.05$ was considered statistically significant.

\section{RESULTS}

\section{MAP-1/MASP-1, -2 and -3 compete for MBL binding}

We investigated the direct competition for MBL binding using checkerboard dilutions of rMAP-1 together with rMASP-1, -2 or -3 . The MAP-1/MASP preparations were coincubated on the MBL/mannan surface in order to mimic the in vivo situation of the formation of an MBL complex with associated proteins on a natural ligand surface. Similar to all three MASPs, we observed a clear tendency that MAP-1, in concentrations above 80 $\mathrm{ng} / \mathrm{ml}$, inhibited MASP binding to MBL (Fig. 2). We observed a very strong dose-dependent inhibitory effect of MAP-1 with an almost complete inhibition of the MASP binding in concentrations above $7 \mu \mathrm{g} / \mathrm{ml}$. We also assessed the inhibition range in MAP-1 concentration $<30 \mathrm{ng} / \mathrm{ml}$, where no inhibition was observed. At concentrations above 20 $\mu \mathrm{g} / \mathrm{ml}$, no additional inhibitory effect was evident (Fig. 2).

\section{MAP-1 preserves myocardial function}

Hearts from MBL null mice are protected from MI/R induced loss of cardiac function compared to WT mice ${ }^{7}$. In contrast, MBL null mice developed a WT phenotype and 
significantly decreased myocardial ejection fraction following MI/R (Fig. 3A) when given rhMBL similar to that previously observed ${ }^{7}$. MAP-1 $(160 \mu \mathrm{g} /$ mouse) significantly prevented MI/R induced loss of cardiac function in rhMBL ( $30 \mu \mathrm{g} /$ mouse) supplemented MBL null mice (Fig. 3A, left panel). Ejection fractions following MI/R in WT mice treated with MAP-1 were significantly higher compared to WT mice treated with saline or a control protein, BSA (Fig. 3A, right panel). We observed a non-significant difference in the ejection fraction in WT mice following MI/R when using $500 \mu \mathrm{g}$ MAP-1/mouse compared to $300 \mu \mathrm{g}$ MAP-1/mouse (Fig. 3B). The data demonstrate a MAP-1 induced protection from MBL induced loss of cardiac function following MI/R.

\section{MAP-1 reduces infarct size}

We also investigated whether MAP-1 protects the myocardium from infarction following $\mathrm{MI} / \mathrm{R}$. As we have previously demonstrated, MBL null mice have very small myocardial infarctions following MI/R (Fig. 4A and 4C) ${ }^{7}$. Addition of rhMBL (30 $\mu \mathrm{g} / \mathrm{mouse}$ ) to MBL null mice increased myocardial infarction size compared to MBL null mice (Fig. 4C). MAP-1 treatment ( $160 \mu \mathrm{g} /$ mouse) of MBL null mice supplemented with rhMBL significantly protected mice from myocardial infarction compared to MBL null + rhMBL mice. Similarly, WT mice treated with control protein (i.e., BSA) undergoing MI/R displayed larger myocardial infarctions compared to MAP-1 treated WT mice (Fig. 4B and 4C). Thus, the natural, endogenous inhibitor, MAP-1, preserves myocardial function, as well as myocardial tissue from the tissue damage associated with $\mathrm{MI} / \mathrm{R}$.

\section{MAP-1 prevents complement activation following MI/R}

Complement activation following MI/R results in $\mathrm{C} 3$ deposition via an MBL complex and MASP-2 dependent mechanism ${ }^{7 ; 23}$. WT mice treated with MAP-1 displayed significantly less C3 deposition following MI/R compared to WT mice treated with control protein (i.e., BSA; Supplementary Fig. 1 online). Thus, as previously demonstrated in vitro ${ }^{25 ; 26}$, MAP-1 also prevents MBL and MASP-2 dependent complement activation in vivo following MI/R.

\section{MAP-1 prevents occlusive arterial thrombogenesis}

Previous studies have demonstrated that $\mathrm{FeCl}_{3}$-induced occlusive thrombogenesis is mediated by the MBL complex and MASP-1 in vivo ${ }^{6 ; 21}$. WT + BSA mice developed occlusive thrombogenesis and succession of carotid artery blood flow 15 minutes following application of $3.5 \% \mathrm{FeCl}_{3}$. WT mice treated with MAP-1 (500 $\mu \mathrm{g} /$ mouse) demonstrated no decrease in carotid artery blood flow following $\mathrm{FeCl}_{3}$ application. These results demonstrate that MAP-1 significantly prevents coagulation in vivo (Fig. 5).

Carotid arteries were harvested to evaluate MBL deposition on the arterial wall as demonstrated previously ${ }^{6}$. MBL-A and MBL-C deposition were observed on the arterial wall of WT mice treated with BSA (Fig. 6, left panel). In contrast, WT mice treated with MAP-1 (500 $\mu \mathrm{g} /$ mouse) displayed significantly reduced deposition of murine MBL and the absence of a thrombus within the artery compared to BSA treated WT mice (Fig. 6, right panel). A lack of staining was observed in isotype control stained arteries, demonstrating the specificity of the mAb rat anti-mouse MBL-A/-C staining (Fig. 6, middle panel). These data support the hypothesis that in addition to preventing assembly of MASP-1, -2 and -3 within the MBL complex, that the MBL complex is also prevented from depositing onto oxidatively stressed arteries.

\section{MAP-1 attenuates MBL deposition on GIcNAc-BSA}

We have previously demonstrated that MAP-1 does not prevent MBL deposition on mannan-coated plates ${ }^{25}$, so the inhibition of MBL deposition on carotid arteries was an 
unexpected observation (Fig. 6). MBL and C3 deposition on mannan-coated plates are summarized in Fig. 7A. MBL and C3 deposition on mannan were significantly inhibited by mAb 3F8. In contrast, MBL deposition on mannan was not inhibited by MAP-1. Consistent with our findings in Fig. 2, MAP-1 significantly attenuated C3 deposition on mannan-coated plates in a dose-related manner. We also investigated whether MAP-1 could inhibit MBL deposition on a structurally different ligand, GlcNAc-BSA. As shown in Fig. 7B, MAP-1(10 $\mu \mathrm{g} / \mathrm{ml}$ ) significantly attenuated MBL deposition and the resulting C3 deposition on GlcNAcBSA. These data demonstrate that in addition to inhibiting MASPs incorporation into the MBL complex, MAP-1 also inhibits MBL deposition on some MBL ligands and inhibits the resulting complement activation and $\mathrm{C} 3$ deposition.

\section{Discussion}

MAP-1, also known as MAp44 ${ }^{26}$, is a recently discovered protein that inhibits lectin complement pathway activation and is highly expressed in striated muscle, including the myocardium ${ }^{25}$. While the functional aspects of this protein is largely unknown, the current study demonstrates that at pharmacologic doses, MAP-1 functions as a novel, endogenous and natural inhibitor of the lectin pathway via several mechanisms. First, the in vitro studies demonstrate that MAP-1 competitively inhibits all three MASPs from interacting with the MBL complex. Second, in vivo MAP-1 also inhibits MBL deposition in the $\mathrm{FeCl}_{3}$ model of occlusive thrombogenesis. Third, MAP-1 effectively inhibits MBL complex mediated pathophysiologic outcomes in vivo following MI/R and inhibits thrombogenesis. Thus, MAP-1 is a novel, endogenous and natural inhibitor of the lectin complement pathway in vivo.

Our data extend previous studies which demonstrate an important role of the MBL complex in myocardial infarction 7;9;10;30;34. MAP-1 in the present study significantly preserved myocardial function, inhibited $\mathrm{C} 3$ deposition and decreased myocardial infarct size in WT mice following MI/R. Along these lines, MASP-2 inhibition or deletion also decreases myocardial infarct size and is responsible for formation of a C3 convertase necessary for $\mathrm{C} 3$ deposition following MBL complex interactions with its ligand ${ }^{23 ; 35}$. MAP-1 dosedependently inhibits MASP-2 association with the MBL complex in the present study and also significantly decreased C3 deposition in vivo following MI/R. Thus, MAP-1, when given at pharmacologic doses, functionally inhibits formation of a functional MBL complex and the resulting complement activation following MI/R in vivo.

While many studies have investigated the role and function of MASP-2 in the activation of the lectin complement pathway, the functions of MASP-1 and MASP-3 have only recently been demonstrated. MASP-1 and -3 activate the alternative complement pathway 12-14;36. Since MAP-1 dose-dependently inhibits assembly of MASP-1 and -3 into the MBL complex, MAP-1 also likely inhibits this amplification loop, which plays a major role in tissue damage and inflammation following ischemia/reperfusion injury ${ }^{37}$. MAP-1's multiple inhibitory mechanisms of action within the complement system make it potentially a very effective and efficient inhibitor before, during and following initiation of complement activation.

MASP-1 and MASP-2 play significant roles in coagulation. MASP-2 and MASP-1 contribute to generation of thrombin from prothrombin ${ }^{19 ; 38}$. MASP-1 dose-dependently cleaves/activates fibrinogen and FXIII albeit at a slower rate than thrombin in vitro ${ }^{38}$. MASP-1 may also stabilize clot formation by activation of TAFI and thus inhibiting fibrinolysis ${ }^{38}$. We have previously demonstrated that MASP-1 is responsible for $\mathrm{FeCl}_{3}$ induced occlusive thrombogenesis in vivo ${ }^{6}$. In the present study, MAP-1 dose-dependently inhibited incorporation of both MASP-1 and MASP-2 into the MBL complex. Further, 
MAP-1 inhibited occlusive thrombogenesis of the carotid artery following $\mathrm{FeCl}_{3}$ application in WT mice. Thus, MAP-1 is a functional, native and endogenous inhibitor of coagulation in vivo.

Interestingly, we also observed that MAP-1 inhibited MBL deposition on the vascular endothelium following $\mathrm{FeCl}_{3}$ application. This was an unexpected observation, as MAP-1 does not prevent MBL binding to mannan (Fig. 7A) and is consistent with our previous findings ${ }^{25}$. In contrast to $\mathrm{mAb} 3 \mathrm{~F} 8$, which inhibits both $\mathrm{MBL}$ and $\mathrm{C} 3$ deposition on mannan, MAP-1 did not inhibit MBL binding to mannan-coated plates, but did dosedependently attenuate $\mathrm{C} 3$ deposition (Figure 7A). The attenuation of $\mathrm{C} 3$ deposition on mannan-coated plates is consistent with the inhibition of MASPs incorporation into the MBL complex as shown in Fig. 2, but does not explain the inhibition of MBL binding in the $\mathrm{FeCl}_{3}$ carotid artery study (Fig. 6). The binding avidity of MBL is significantly higher to mannan compared to GlcNAc-BSA ${ }^{39}$. We hypothesize that MAP-1 may inhibit MBL binding on MBL ligands that display lower avidity binding. Indeed, we observed that MAP-1 significantly attenuated MBL and C3 deposition on GlcNAc-BSA coated plates. The GlcNAc-BSA complex is a MBL ligand that displays lower avidity compared to mannan, probably due to the irregular spacing of the GlcNAc attached to BSA. These data suggest that MAP-1, in addition to inhibition of MASPs incorporation into MBL complexes, also attenuates MBL binding onto some ligands, which could particularly be relevant towards endogenous ligands.

In the present study, we demonstrate multiple functional aspects of MAP-1 in vivo, which are graphically represented in Fig. 1. In addition to attenuating myocardial injury and complement activation following myocardial ischemia and reperfusion, MAP-1 functionally inhibits occlusive thrombogenesis in vivo. Thus, MAP-1 has a variety of inhibitory properties associated with the MBL complex, particularly MASP-1, MASP-2 and MASP-3. These three serine proteases are also associated with the ficolins, which leads to complement activation and likely other biological activities ${ }^{40}$. We cannot exclude additional inhibitory functions of MAP-1 that may be associated with MASPs activity. The present data clearly demonstrate the native, natural, endogenous inhibitor MAP-1 has multiple functional outcomes associated with coagulation and complement activation in vivo. These pharmacologic actions may have a significant impact in the treatment of cardiovascular diseases associated with complement and coagulation abnormalities.

\section{Supplementary Material}

Refer to Web version on PubMed Central for supplementary material.

\section{Acknowledgments}

We acknowledge the expert technical assistance of Margaret Morrissey during the course of these studies. We thank Dr. Lea Munthe-Fog for help with graphical design.

FUNDING SOURCES: This work was supported in part by NIH grants AI089781, HL056086, HL099130, The Novo Nordisk Research Foundation, The Svend Andersen Research Foundation, The Danish Medical Research Council and The Research Foundation of the Capital Region of Denmark.

\section{References}

1. Janeway CA Jr, Medzhitov R. Innate immune recognition. Annu Rev Immunol. 2002; 20:197-216. [PubMed: 11861602]

2. Holmskov U, Thiel S, Jensenius JC. Collections and ficolins: humoral lectins of the innate immune defense. Annu Rev Immunol. 2003; 21:547-578. [PubMed: 12524383] 
3. Mevorach D. Opsonization of apoptotic cells. Implications for uptake and autoimmunity. Ann N Y Acad Sci. 2000; 926:226-235. [PubMed: 11193038]

4. Collard CD, Vakeva A, Morrissey MA, Agah A, Rollins SA, Reenstra WR, Buras JA, Meri S, Stahl GL. Complement activation following oxidative stress: Role of the lectin complement pathway. Am J Pathol. 2000; 156:1549-1556. [PubMed: 10793066]

5. Pavlov VI, La Bonte LR, Baldwin WM, Markiewski M, Lambris J, Stahl GL. Absence of mannosebinding lectin prevents hyperglycemic cardiovascular complications. Am J Pathol. 2012; 180:104112. [PubMed: 22079428]

6. La Bonte LR, Pavlov VI, Tan YS, Takahashi K, Takahashi M, Banda NK, Zou C, Fujita T, Stahl GL. Mannose-binding lectin-associated serine protease-1 is a significant contributor to coagulation in a murine model of occlusive thrombosis. J Immunol. 2012; 188:885-891. [PubMed: 22156595]

7. Walsh MC, Bourcier T, Takahashi K, Shi L, Busche MN, Rother RP, Solomon SD, Ezekowitz RA, Stahl GL. Mannose-binding lectin is a regulator of inflammation that accompanies myocardial ischemia and reperfusion injury. J Immunol. 2005; 175:541-546. [PubMed: 15972690]

8. McMullen ME, Hart ML, Walsh MC, Buras J, Takahashi K, Stahl GL. Mannose-binding lectin binds IgM to activate the lectin complement pathway in vitro and in vivo. Immunobiology. 2006; 211:759-766. [PubMed: 17113913]

9. Busche MN, Walsh MC, McMullen ME, Guikema BJ, Stahl GL. Mannose-binding lectin plays a critical role in myocardial ischaemia and reperfusion injury in a mouse model of diabetes. Diabetologia. 2008; 51:1544-1551. [PubMed: 18493734]

10. Jordan JE, Montalto MC, Stahl GL. Inhibition of mannose-binding lectin reduces postischemic myocardial reperfusion injury. Circulation. 2001; 104:1413-1418. [PubMed: 11560858]

11. Liu H, Jensen L, Hansen S, Petersen SV, Takahashi K, Ezekowitz AB, Hansen FD, Jensenius JC, Thiel S. Characterization and quantification of mouse mannan-binding lectins (MBL-A and MBLC) and study of acute phase responses. Scand J Immunol. 2001; 53:489-497. [PubMed: 11309157]

12. Takahashi M, Iwaki D, Kanno K, Ishida Y, Xiong J, Matsushita M, Endo Y, Miura S, Ishii N, Sugamura K, Fujita T. Mannose-binding lectin (MBL)-associated serine protease (MASP)-1 contributes to activation of the lectin complement pathway. J Immunol. 2008; 180:6132-6138. [PubMed: 18424734]

13. Takahashi M, Ishida Y, Iwaki D, Kanno K, Suzuki T, Endo Y, Homma Y, Fujita T. Essential role of mannose-binding lectin-associated serine protease-1 in activation of the complement factor D. $\mathrm{J}$ Exp Med. 2010; 207:29-3. [PubMed: 20038603]

14. Iwaki D, Kanno K, Takahashi M, Endo Y, Matsushita M, Fujita T. The role of mannose-binding lectin-associated serine protease- 3 in activation of the alternative complement pathway. $\mathrm{J}$ Immunol. 2011; 187:3751-3758. [PubMed: 21865552]

15. Chen CB, Wallis R. Two mechanisms for mannose-binding protein modulation of the activity of its associated serine proteases. J Biol Chem. 2004; 279:26058-26065. [PubMed: 15060079]

16. Dobo J, Major B, Kekesi KA, Szabo I, Megyeri M, Hajela K, Juhasz G, Zavodszky P, Gal P. Cleavage of kininogen and subsequent bradykinin release by the complement component: mannose-binding lectin-associated serine protease (MASP)-1. PLoS ONE. 2011; 6:e20036. [PubMed: 21625439]

17. Gulla KC, Gupta K, Krarup A, Gal P, Schwaeble WJ, Sim RB, O’Connor CD, Hajela K. Activation of mannan-binding lectin-associated serine proteases leads to generation of a fibrin clot. Immunology. 2010; 129:482-495. [PubMed: 20002787]

18. Megyeri M, Mako V, Beinrohr L, Doleschall Z, Prohaszka Z, Cervenak L, Zavodszky P, Gal P. Complement protease MASP-1 activates human endothelial cells: PAR4 activation is a link between complement and endothelial function. J Immunol. 2009; 183:3409-3416. [PubMed: 19667088]

19. Krarup A, Wallis R, Presanis JS, Gal P, Sim RB. Simultaneous activation of complement and coagulation by MBL-associated serine protease 2. PLoS ONE. 2007; 2:e623. [PubMed: 17637839]

20. Krarup A, Gulla KC, Gal P, Hajela K, Sim RB. The action of MBL-associated serine protease 1 (MASP1) on factor XIII and fibrinogen. Biochim Biophys Acta. 2008; 1784:1294-1300. [PubMed: 18456010] 
21. Takahashi K, Chang WC, Takahashi M, Pavlov V, Ishida Y, La Bonte LR, Shi L, Fujita T, Stahl GL, Van Cott EM. Mannose-binding lectin and its associated proteases (MASPs) mediate coagulation and its deficiency is a risk factor in developing complications from infection, including disseminated intravascular coagulation. Immunobiology. 2011; 216:96-102. [PubMed: 20399528]

22. Davis AE III. Biological effects of C1 inhibitor. Drug News Perspect. 2004; 17:439-446. [PubMed: 15514703]

23. Schwaeble WJ, Lynch NJ, Clark JE, Marber M, Samani NJ, Ali YM, Dudler T, Parent B, Lhotta K, Wallis R, Farrar CA, Sacks S, Lee H, Zhang M, Iwaki D, Takahashi M, Fujita T, Tedford CE, Stover CM. Targeting of mannan-binding lectin-associated serine protease- 2 confers protection from myocardial and gastrointestinal ischemia/reperfusion injury. Proc Natl Acad Sci U S A. 2011; 108:7523-7528. [PubMed: 21502512]

24. Fujita T. Evolution of the lectin-complement pathway and its role in innate immunity. Nat Rev Immunol. 2002; 2:346-353. [PubMed: 12033740]

25. Skjoedt MO, Hummelshoj T, Palarasah Y, Honore C, Koch C, Skjodt K, Garred P. A novel MBL/ ficolin associated protein is highly expressed in heart and skeletal muscle tissues and inhibits complement activation. J Biol Chem. 2010; 285:8234-8243. [PubMed: 20053996]

26. Degn SE, Hansen AG, Steffensen R, Jacobsen C, Jensenius JC, Thiel S. MAp44, a human protein associated with pattern recognition molecules of the complement system and regulating the lectin pathway of complement activation. J Immunol. 2009; 183:7371-7378. [PubMed: 19917686]

27. Skjoedt MO, Hummelshoj T, Palarasah Y, Hein E, Munthe-Fog L, Koch C, Skjodt K, Garred P. Serum concentration and interaction properties of MBL/ficolin associated protein-1. Immunobiology. 2011; 216:625-632. [PubMed: 21035894]

28. Gorsuch WB, Guikema BJ, Fritzinger DC, Vogel C-W, Stahl GL. Humanized cobra venom factor decreases myocardial ischemia-reperfusion injury. Mol Immunol. 2009; 47:506-510. [PubMed: 19747734]

29. Vakeva AP, Agah A, Rollins SA, Matis LA, Li L, Stahl GL. Myocardial infarction and apoptosis after myocardial ischemia and reperfusion. Role of the terminal complement components and inhibition by anti-C5 therapy. Circulation. 1998; 97:2259-2267. [PubMed: 9631876]

30. Busche MN, Pavlov V, Takahashi K, Stahl GL. Myocardial ischemia and reperfusion injury is dependent on both IgM and mannose-binding lectin. Am J Physiol Heart Circ Physiol. 2009; 297:H1853-H1859. [PubMed: 19749170]

31. Westrick RJ, Winn ME, Eitzman DT. Murine models of vascular thrombosis (Eitzman series). Arterioscler Thromb Vasc Biol. 2007; 27:2079-2093. [PubMed: 17600224]

32. Wang X, Xu L. An optimized murine model of ferric chloride-induced arterial thrombosis for thrombosis research. Thromb Res. 2005; 115:95-100. [PubMed: 15567459]

33. Walsh MC, Shaffer LA, Guikema BJ, Body SC, Shernan SK, Fox AA, Collard CD, Fung M, Taylor RP, Stahl GL. Fluorochrome-linked immunoassay for functional analysis of the mannose binding lectin complement pathway to the level of C3 cleavage. J Immunol Meth. 2007; 323:147159.

34. La Bonte LR, Dokken B, Davis-Gorman G, Stahl GL, McDonagh PF. The mannose-binding lectin pathway is a significant contributor to reperfusion injury in the type 2 diabetic heart. Diab Vasc Dis Res. 2009; 6:172-180. [PubMed: 20216929]

35. Thiel S, Vorup-Jensen T, Stover CM, Schwaeble W, Laursen SB, Poulsen K, Willis AC, Eggleton P, Hansen S, Holmskov U, Reid KB, Jensenius JC. A second serine protease associated with mannan-binding lectin that activates complement. Nature. 1997; 386:506-510. [PubMed: 9087411]

36. Banda NK, Takahashi M, Takahashi K, Stahl GL, Hyatt S, Glogowska M, Wiles TA, Endo Y, Fujita T, Holers VM, Arend WP. Mechanisms of mannose-binding lectin-associated serine proteases-1/3 activation of the alternative pathway of complement. Mol Immunol. 2011; 49:281289. [PubMed: 21943708]

37. Stahl GL, Xu Y, Hao L, Miller M, Buras JA, Fung M, Zhao H. Role for the alternative complement pathway in ischemia/reperfusion injury. Am J Pathol. 2003; 162:449-455. [PubMed: 12547703] 
38. Hess K, Ajjan R, Phoenix F, Dobo J, Gal P, Schroeder V. Effects of MASP-1 of the Complement System on Activation of Coagulation Factors and Plasma Clot Formation. PLoS ONE. 2012; 7:e35690. [PubMed: 22536427]

39. Michelow IC, Dong M, Mungall BA, Yantosca LM, Lear C, Ji X, Karpel M, Rootes CL, Brudner M, Houen G, Eisen DP, Kinane TB, Takahashi K, Stahl GL, Olinger GG, Spear GT, Ezekowitz RA, Schmidt EV. A Novel L-ficolin/Mannose-binding Lectin Chimeric Molecule with Enhanced Activity against Ebola Virus. J Biol Chem. 2010; 285:24729-24739. [PubMed: 20516066]

40. Kuraya M, Ming Z, Liu X, Matsushita M, Fujita T. Specific binding of L-ficolin and H-ficolin to apoptotic cells leads to complement activation. Immunobiology. 2005; 209:689-697. [PubMed: 15804047] 


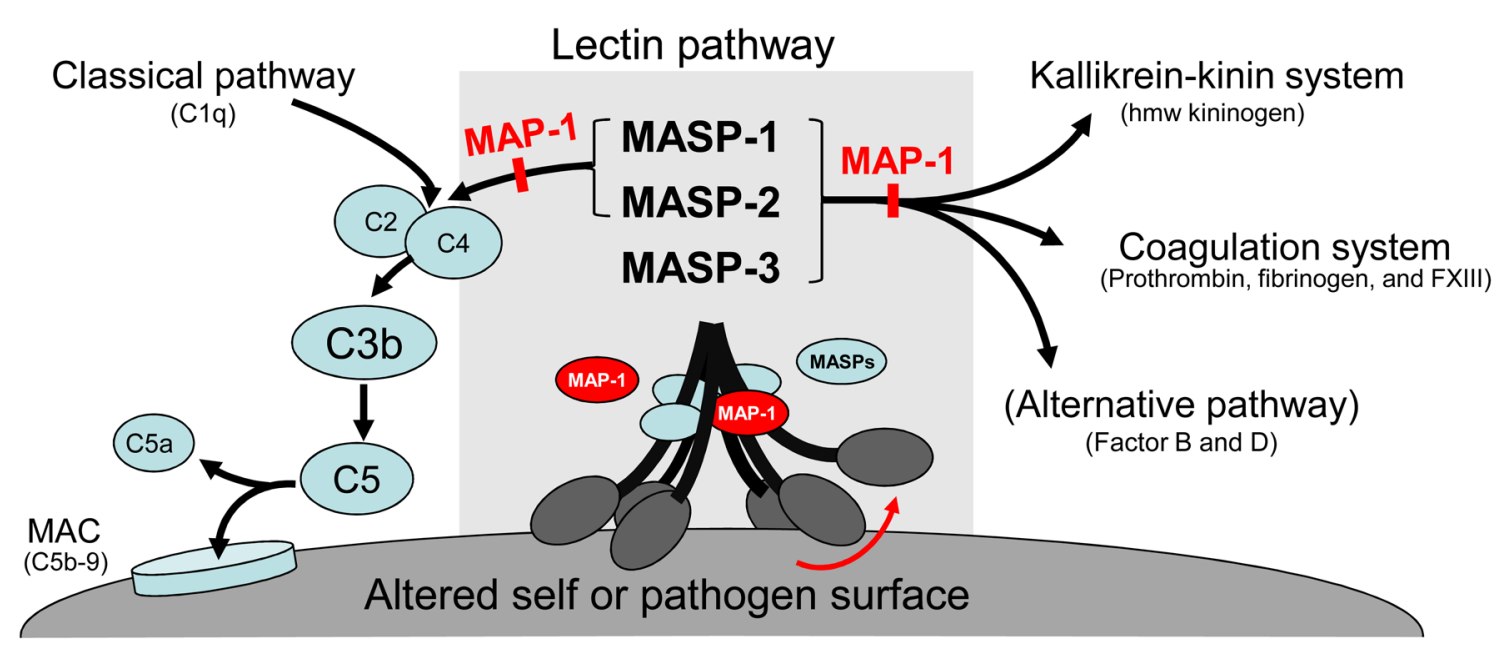

Figure 1.

A model of the recognition molecules MBL and the ficolins in association with the MBL/ ficolin associated serine proteases (MASPs) is shown. The possible roles of the MASPs in activation of the complement system and other cascade systems and subsequent MBL/ficolin associated protein-1 (MAP-1) inhibition are indicated. The direct MASP mediated activation of the alternative pathway has so far only been shown in rodents. In addition, MAP-1 also appears to attenuate binding of the recognition molecules to certain ligands as indicated. Hmw $=$ high molecular weight. 
Fig A: MAP-1 compact on MBL:MASP-1 complex formation

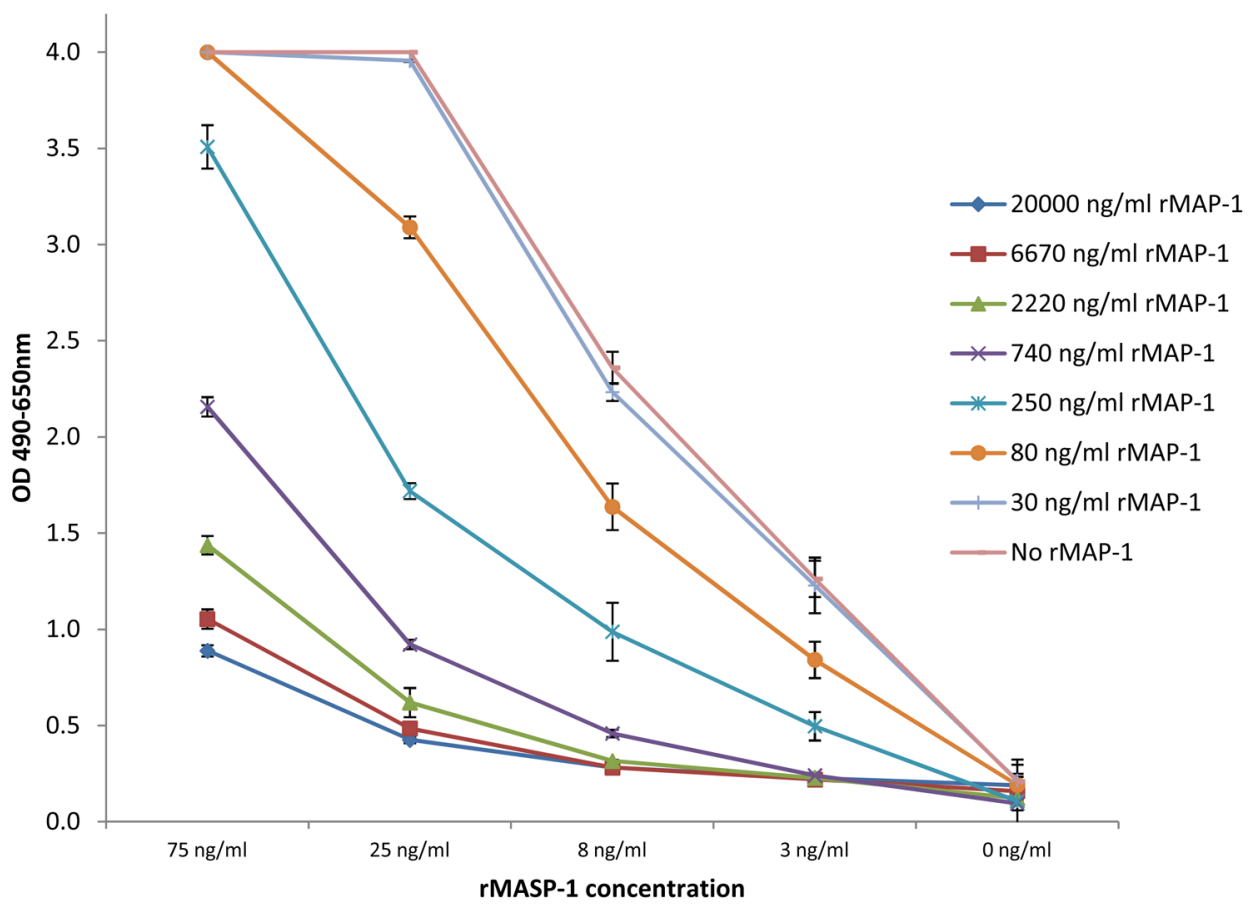

Fig. B: MAP-1 impact on MBL:MASP-2 complex formation

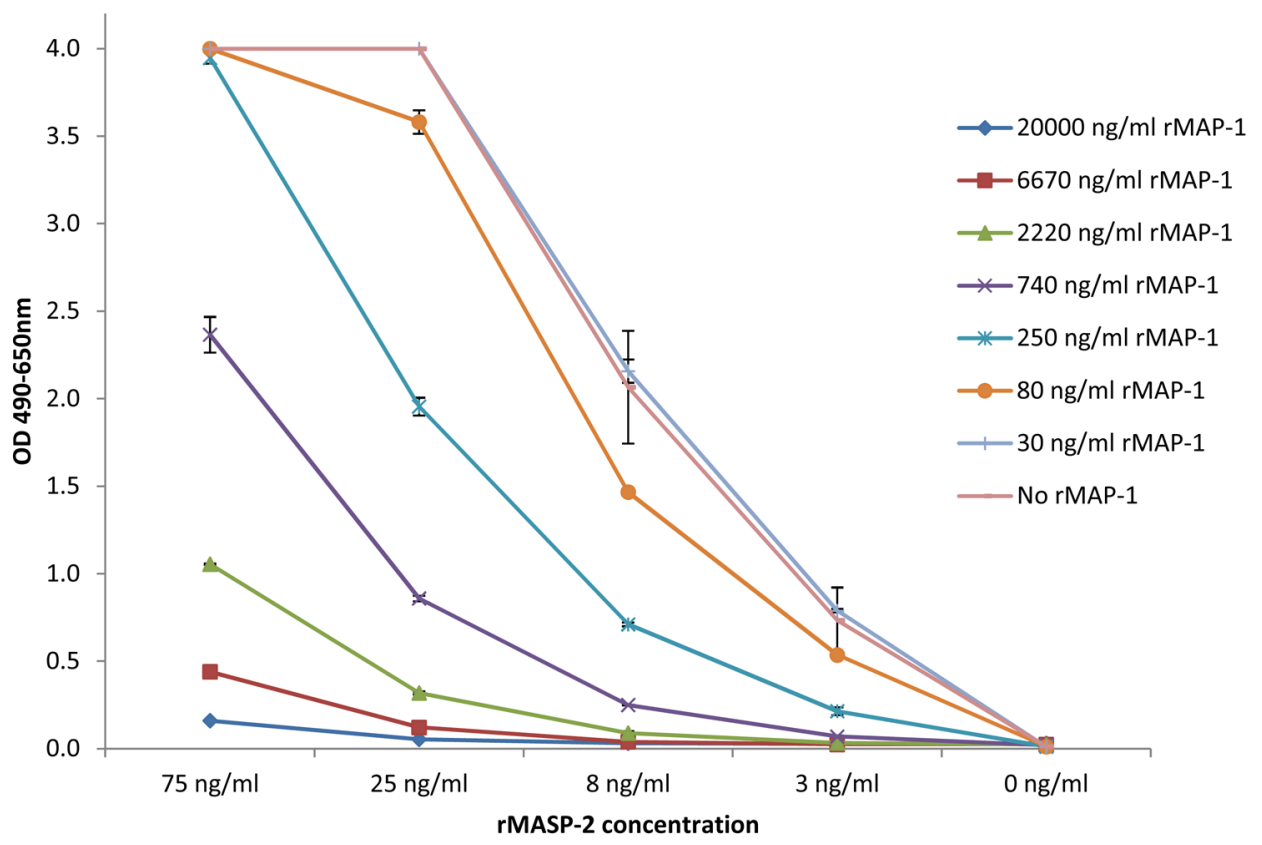

Circulation. Author manuscript; available in PMC 2013 October 30. 
Fig. C: MAP-1 impact on MBL:MASP-3 complex formation

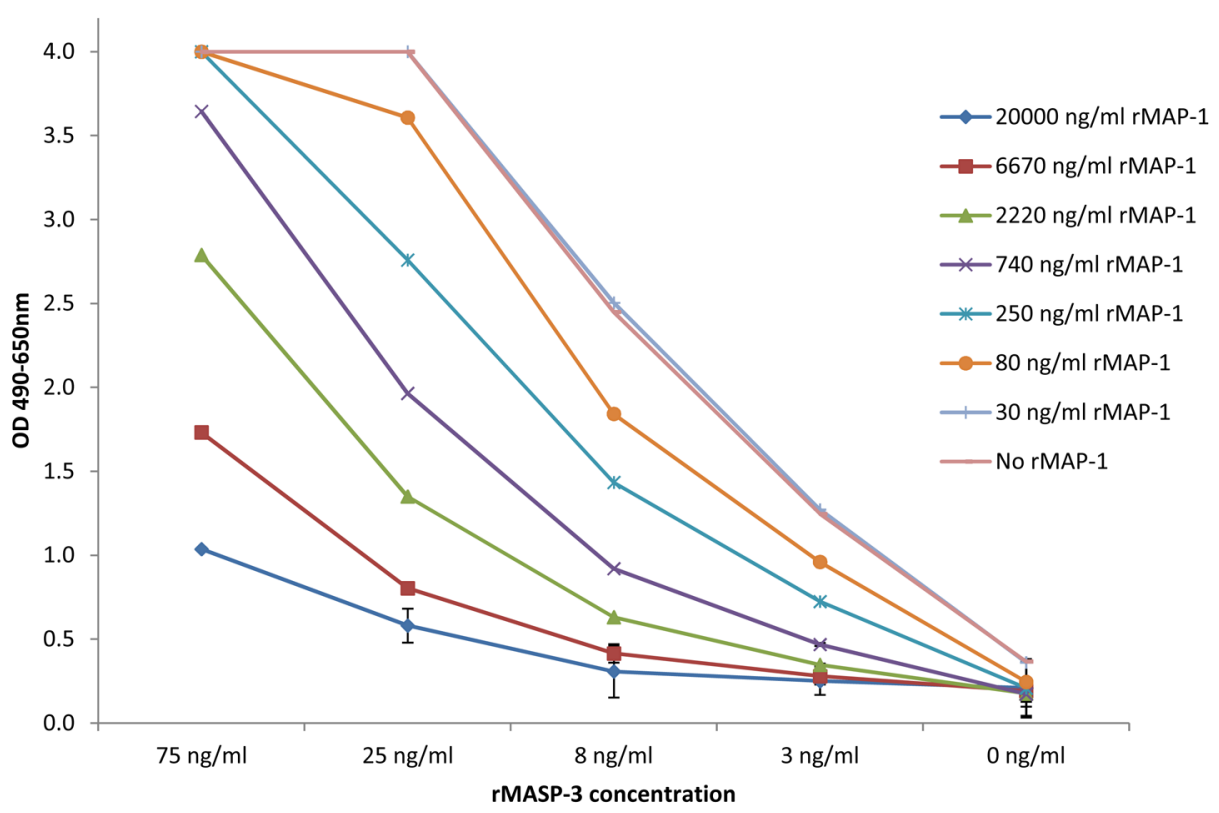

Figure 2.

Influence of MAP-1 on complex formation between MBL and MASP-1 (Panel 2A), MASP-2 (Panel 2B) and MASP-3 (Panel 2C). rMBL was pre-incubated on immobilized mannan before application of pre-mixed serial dilutions of MAP-1 with MASP-1, -2 , or -3. The level of MASP binding to MBL was detected by anti-MASP mAbs, and measured as OD490-650nm. Error bars indicate two times the standard deviation of duplicate determinations. 


\section{Panel A}

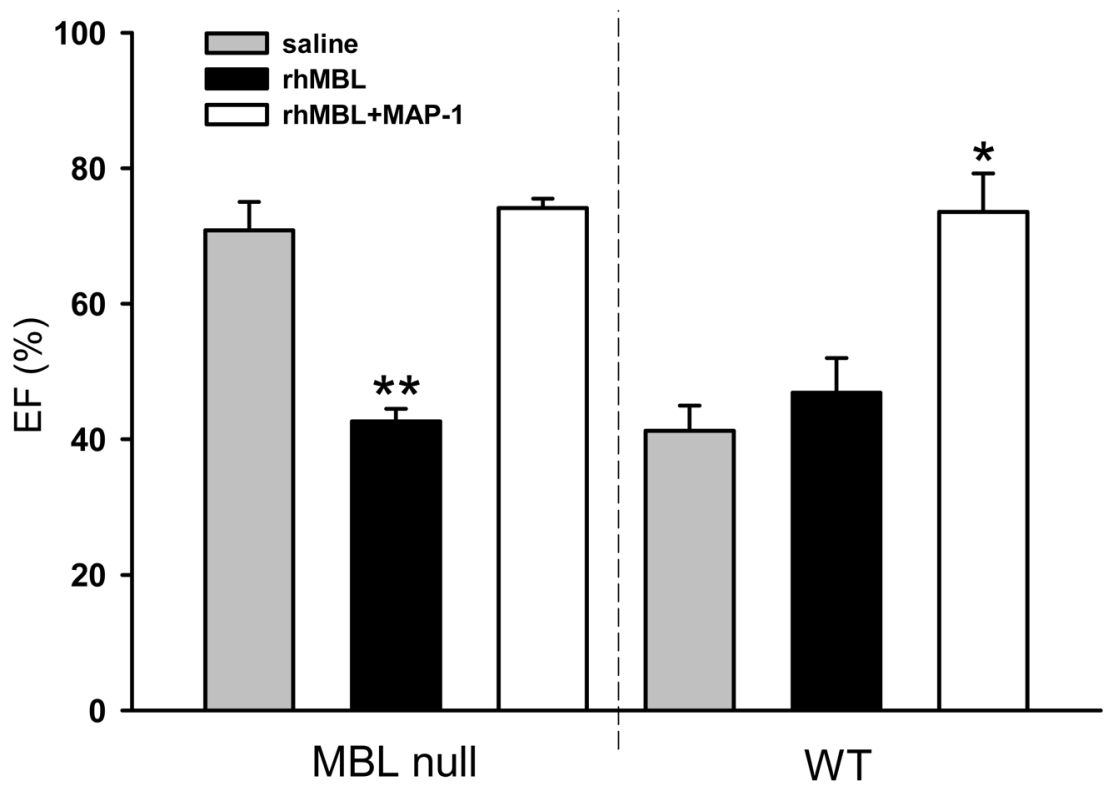

\section{Panel B}

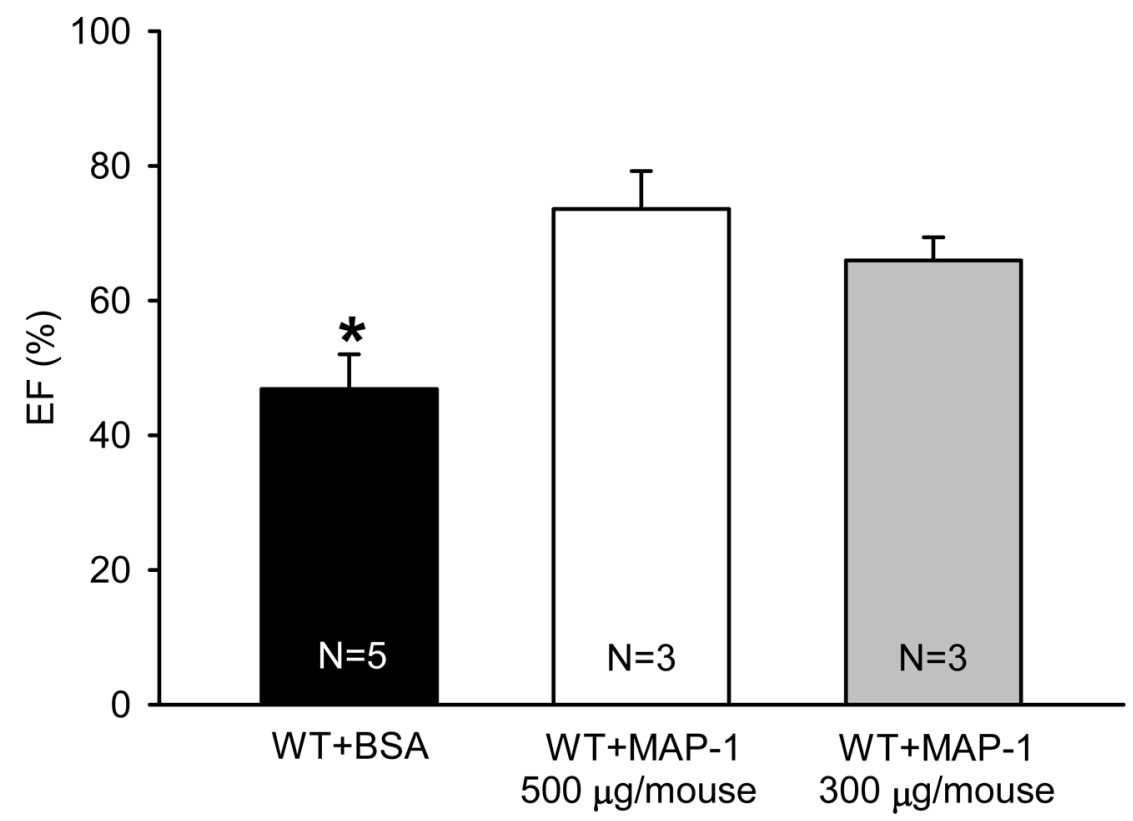

Figure 3.

Myocardial ejection fraction (EF) measurements. EF was assessed after 45 minutes ischemia and 4 hours of reperfusion.

Panel 3A. Summary of murine myocardial ejection fraction data for MBL null (n=3), MBL null + rhMBL (30 $\mu \mathrm{g} /$ mouse, ip; $\mathrm{n}=3)$, MBL null + rhMBL $(30 \mu \mathrm{g} / \mathrm{mouse}, \mathrm{ip})+$ MAP-1 (160 $\mu \mathrm{g} /$ mouse, ip; $\mathrm{n}=3)$, and WT + bovine serum albumin (BSA, $500 \mu \mathrm{g} /$ mouse, ip; $\mathrm{n}=5$ ), $\mathrm{WT}+$ saline $(\mathrm{n}=3), \mathrm{WT}+\mathrm{MAP}-1(500 \mu \mathrm{g} /$ mouse, $\mathrm{ip} ; \mathrm{n}=3)$. All data are mean \pm 
SEM. ${ }^{*} \mathrm{P}<0.05$ compared to $\mathrm{WT}+$ saline or $\mathrm{WT}+\mathrm{BSA}$; ${ }^{* *} \mathrm{P}<0.001$ compared to MBL null or MBL null+rhMBL+MAP-1.

Panel 3B. Summary of murine myocardial ejection fraction data for WT + BSA (500 $\mu \mathrm{g} /$ mouse, ip), MBL null + MAP-1 (300 or $500 \mu \mathrm{g} /$ mouse, ip) following MI/R. All data are mean \pm SEM of $\mathrm{N}$ experiments/group. ${ }^{*} \mathrm{P}<0.05$ compared to WT + MAP-1 at 300 or $500 \mu \mathrm{g} /$ mouse. 

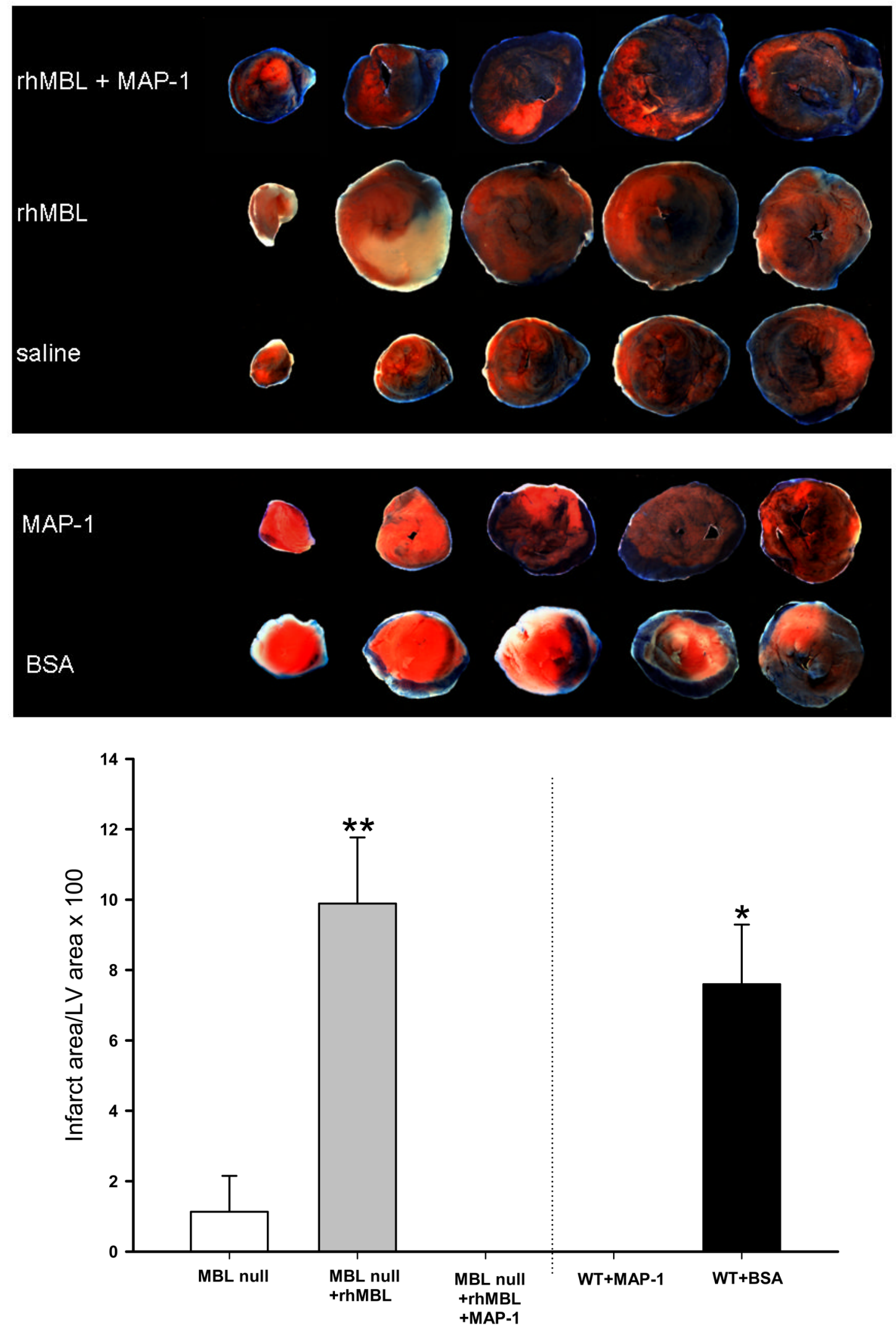

Circulation. Author manuscript; available in PMC 2013 October 30. 


\section{Figure 4.}

Assessment of myocardial infarction following MI/R in MBL null and WT mice. Brilliant Blue $G$ dye (blue) denotes the non-ischemic area, whereas red and white demonstrate the area at risk (ischemic tissue). White (unstained) tissue denotes infarcted tissue and red denotes viable tissue.

Panel 4A. Representative myocardial sections (apex to base) from individual hearts following staining for infarcted tissue in MBL null mice treated with rhMBL, rhMBL +MAP-1 or saline.

Panel 4B. Representative myocardial sections (apex to base) from individual hearts following staining for infarcted tissue in WT mice treated with MAP-1 (500 $\mu \mathrm{g} / \mathrm{mouse}$, ip) or control protein (BSA, $500 \mu \mathrm{g} / \mathrm{mouse}$, ip).

Panel 4C. Percentage of infarcted LV. The percentage of the infarcted area was calculated from weight of the LV, AAR, area of infarct, and non-infarct area. The AAR was not significantly different within the groups. All data are mean \pm SEM of $N=3$ /group. $* * \mathrm{P}<0.001$ compared to MBL null + rhMBL + MAP-1 or MBL null; $* \mathrm{P}<0.01$ compared to $\mathrm{WT}+\mathrm{rhMBL}$ 


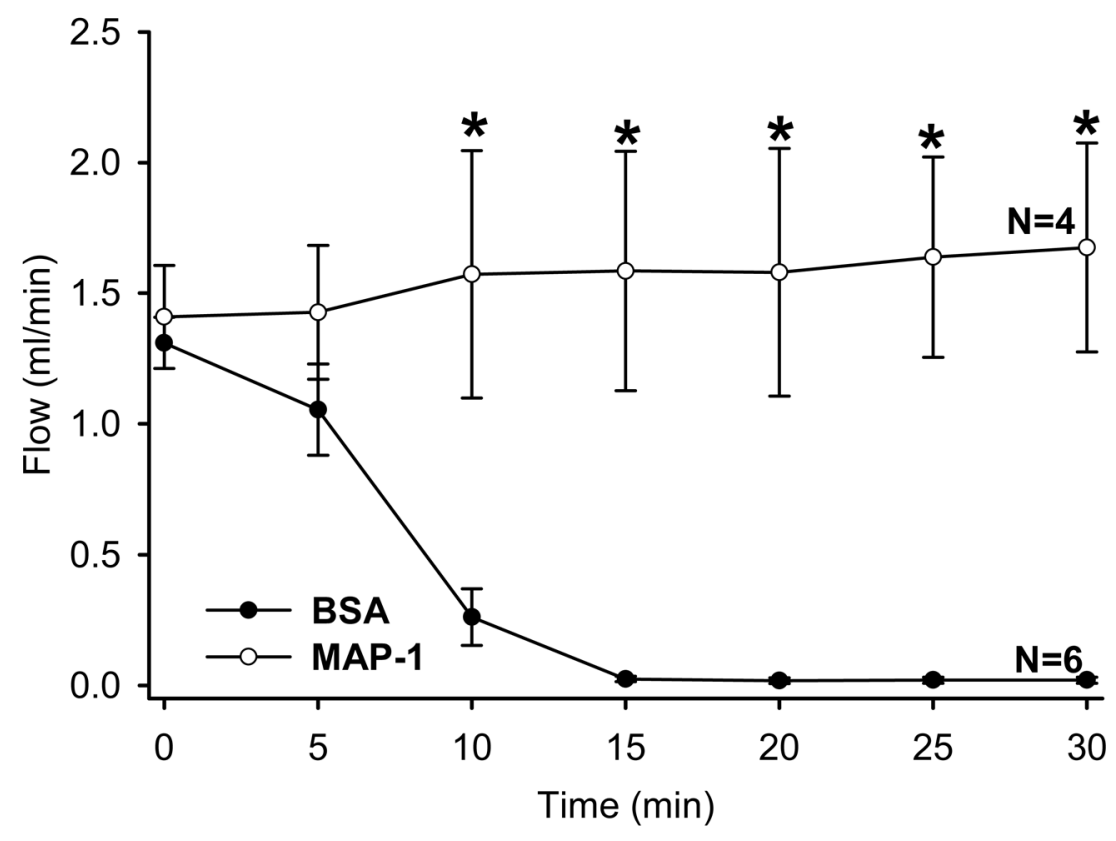

Figure 5.

MAP-1 inhibits $\mathrm{FeCl}_{3}$-induced thrombogenesis in vivo. WT mice were treated with MAP-1 or BSA $\left(500 \mu \mathrm{g} /\right.$ mouse, ip) two hours before application of $\mathrm{FeCl}_{3}$ to the carotid artery. Blood flow was continuously monitored in both groups for 30 minutes following $\mathrm{FeCl}_{3}$ application. Data are mean \pm SEM from $\mathrm{N}=4-6$ mice/group. $* \mathrm{P}<0.001$ compared to BSA. 


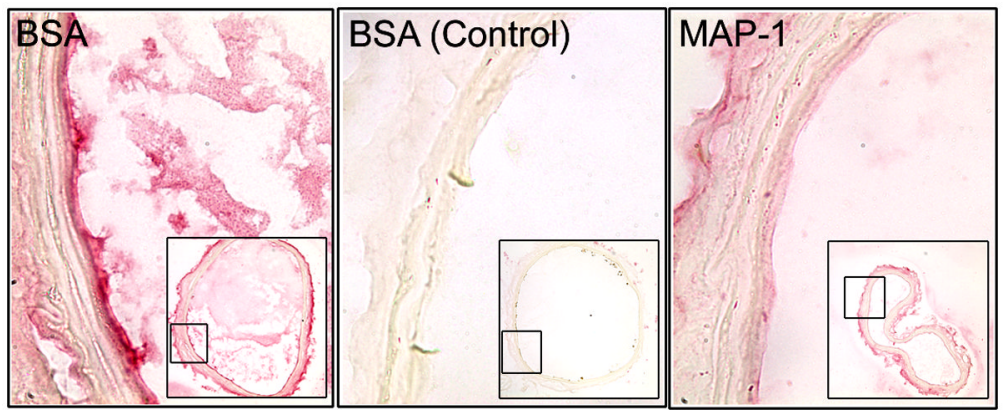

Figure 6.

MBL-A and $-\mathrm{C}$ deposition on carotid artery endothelial cells following $\mathrm{FeCl}_{3}$ application. Arteries were removed 30 minutes following $\mathrm{FeCl}_{3}$ application and stained for murine MBL-A/C. Representative micrographs demonstrate MBL-A/C deposition (red) on the endothelium of the carotid arteries in BSA treated (left panel) mice compared to MAP-1 treated (right panel) mice. The middle panel is a control stained artery from a BSA treated mouse and stained with isotype control primary antibody (Control) instead of the anti-MBL$\mathrm{A}$ and $-\mathrm{C}$ antibodies (magnification X40 for insert and X100 for the marked section). 

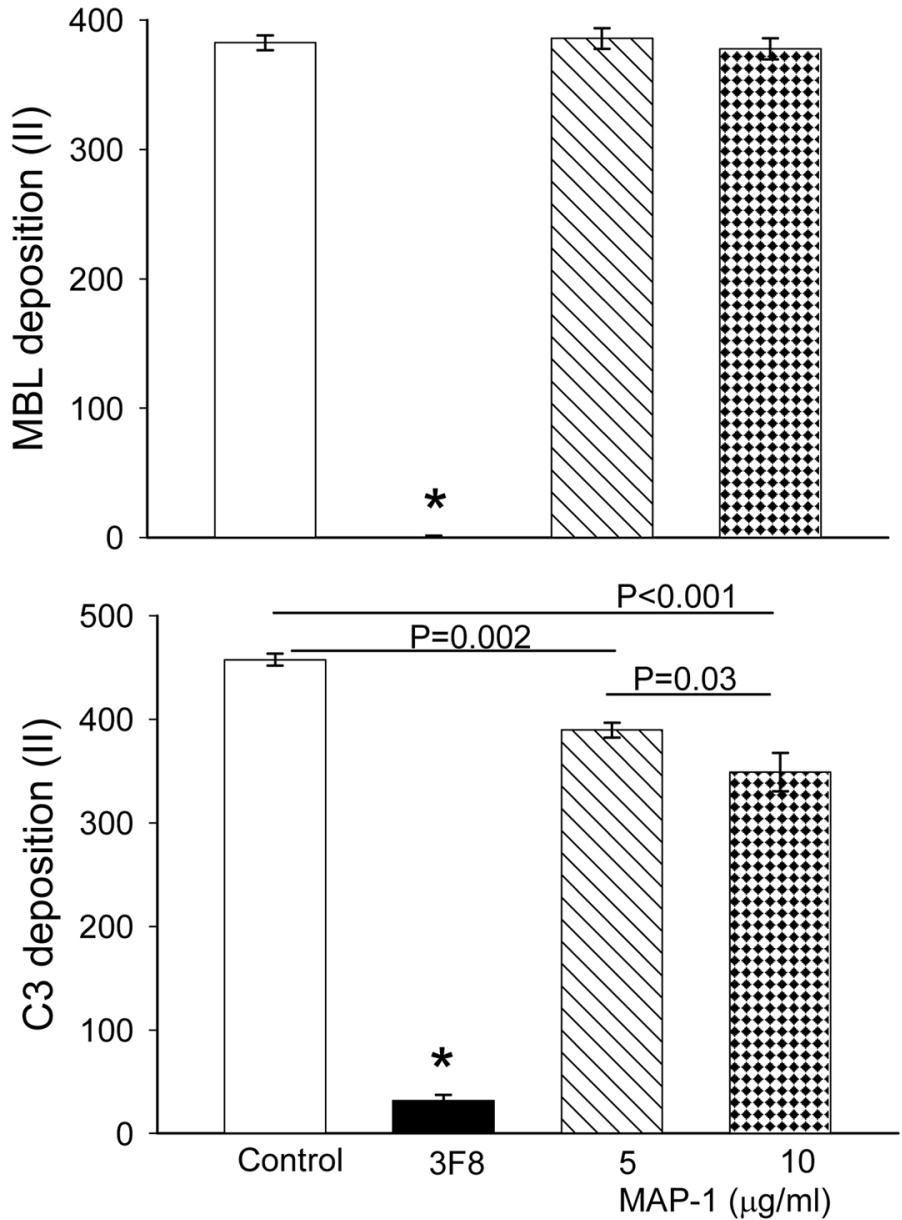


\section{Panel B}
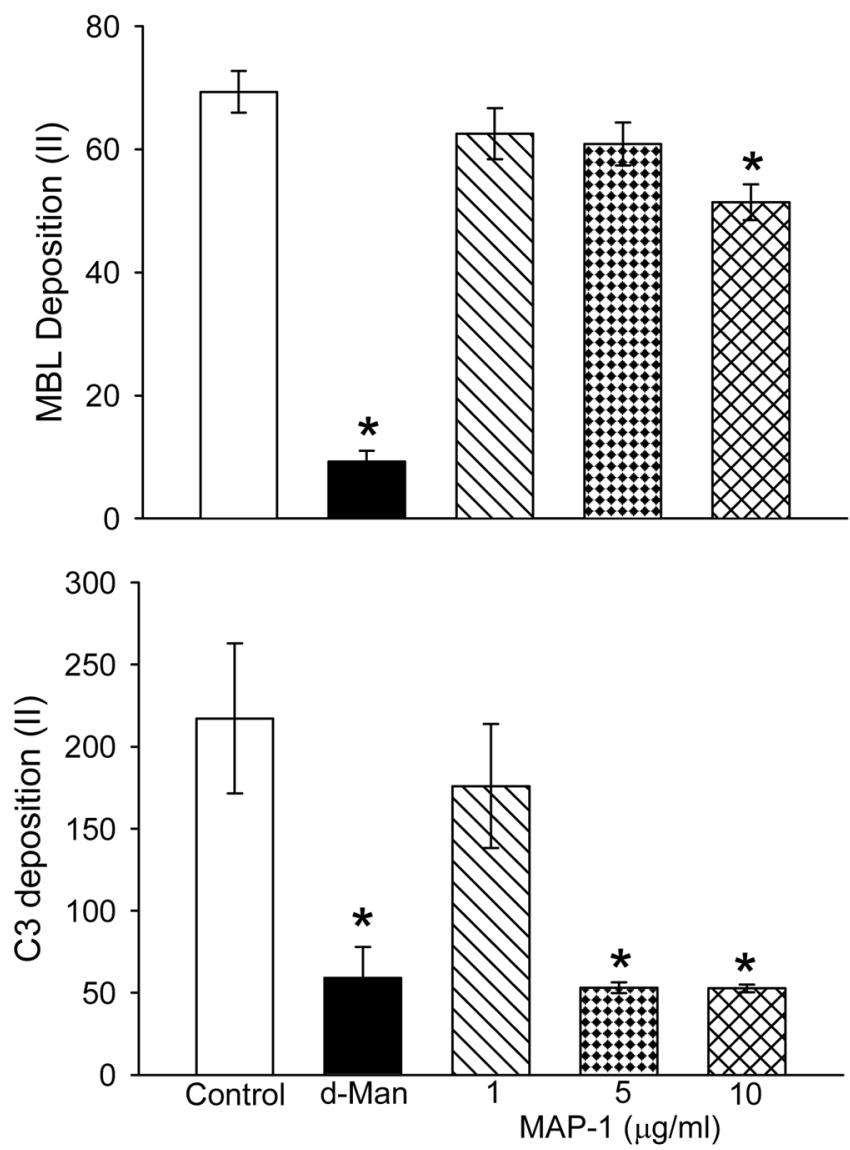

Figure 7.

MBL and MBL-dependent C3 deposition on mannan (Panel A) or GlcNAc-BSA (Panel B) coated plates.

\section{Panel A.}

On mannan-coated plates (Panel A), mAb 3F8 $(10 \mu \mathrm{g} / \mathrm{ml})$, significantly inhibited MBL (upper panel) and C3 deposition (lower panel). MAP-1 did not inhibit MBL deposition on mannan-coated plates but significantly attenuated C3 deposition in a dose-related manner. $* \mathrm{P}<0.001$ compared to all groups within the same panel. Other statistical comparisons are present within the figure panel. $\mathrm{II}=$ integrated intensity. $\mathrm{N}=3$ in triplicate

Panel B. On GlcNAc-BSA coated plates D-mannose (d-Man; $30 \mathrm{mM}$ ) significantly attenuated MBL and C3 deposition. MAP-1 (10 $\mu \mathrm{g} / \mathrm{ml})$ significantly attenuated MBL deposition. MAP-1 (5 or $10 \mu \mathrm{g} / \mathrm{ml}$ ) significantly attenuated C3 deposition on GlcNAc-BSA plates. D-mannose was used as a control, as it will not inhibit potential ficolin induced C3 deposition on GlcNAc-BSA. *P<0.001 compared to Control; II=integrated intensity; $\mathrm{N}=5$ in triplicate 